Available online at

SciVerse ScienceDirect

www.sciencedirect.com
Elsevier Masson France

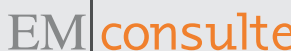

www.em-consulte.com/en

Original article

\title{
Induction of cancer cell death by apoptosis and slow release of 5-fluoracil from metal-organic frameworks Cu-BTC
}

\author{
Flávia Raquel Santos Lucena a,*, Larissa C.C. de Araújo ${ }^{a}$, Maria do D. Rodrigues a, \\ Teresinha G. da Silva ${ }^{a}$, Valéria R.A. Pereira ${ }^{b}$, Gardênia C.G. Militão ${ }^{c}$, Danilo A.F. Fontes ${ }^{\mathrm{d}}$, \\ Pedro J. Rolim-Neto ${ }^{d}$, Fausthon F. da Silva ${ }^{e}$, Silene C. Nascimento ${ }^{\text {a }}$ \\ ${ }^{a}$ Antibiotics Department, Pernambuco Federal University, 50670-901 Recife-PE, Brazil \\ ${ }^{\mathrm{b}}$ Immunology Department, Pernambuco Federal University, 50670-901 Recife-PE, Brazil \\ ' Physiology and Pharmacology Department, Pernambuco Federal University, 50670-901 Recife-PE, Brazil \\ ${ }^{d}$ Pharmaceutical Sciences Department, Pernambuco Federal University, 50590-470 Recife-PE, Brazil \\ e Fundamental Chemistry Department, Pernambuco Federal University, 50590-470 Recife-PE, Brazil
}

\section{A R T I C L E I N F O}

\section{Article history:}

Received 14 May 2013

Accepted 17 June 2013

\section{Keywords:}

Cu-BTC MOF

5-fluorouracil

Apoptosis

Anti-inflammatory and cytotoxic activities

Slow release

\begin{abstract}
A B S T R A C T
This study aimed to evaluate the mechanism associated with cytotoxic activity displayed by the drug 5fluorouracil incorporated in Cu-BTC MOF and its slow delivery from the Cu-BTC MOF. Structural characterization encompasses elemental analysis (CHNS), differential scanning calorimetry (DSC), thermogravimetric analysis (TG/DTG), Fournier transform infrared (FIT-IR) and X-ray diffraction (XRD) was performed to verify the process of association between the drug 5-FU and Cu-BTC MOF. Flow cytometry was done to indicate that apoptosis is the mechanism responsible for the cell death. The release profile of the drug 5-FU from Cu-BTC MOF for 48 hours was obeisant. Also, the anti-inflammatory activity was evaluated by the peritonitis testing and the production of nitric oxide and pro-inflammatory cytokines were measured. The chemical characterization of the material indicated the presence of drug associated with the coordination network in a proportion of $0.82 \mathrm{~g} \mathrm{5-FU} \mathrm{per} 1.0 \mathrm{~g}$ of Cu-BTC MOF. The cytotoxic tests were carried out against four cell lines: NCI-H292, MCF-7, HT29 and HL60. The Cu-BTC MOF associated drug was extremely cytotoxic against the human breast cancer adenocarcinoma (MCF7) cell line and against human acute promyelocytic leukemia cells (HL60), cancer cells were killed by apoptosis mechanisms. The drug demonstrated a slow release profile where $82 \%$ of the drug was released in 48 hours. The results indicated that the drug incorporated in Cu-BTC MOF decreased significantly the number of leukocytes in the peritoneal cavity of rodents as well as reduced levels of cytokines and nitric oxide production.
\end{abstract}

(c) 2013 Elsevier Masson SAS. All rights reserved.

\section{Introduction}

5-fluorouracil (5-FU), a pyrimidine analog, is one of the broad spectrum anticancer drugs [1-3] used in the treatment of malignancies like glioblastoma [4] and breast cancer [5]. Since 5-FU interferes with DNA synthesis, it principally acts as a thymidylate synthase inhibitor [6,7]. However, short half-life, wide distribution, and various side effects limit its medical applicability [8-10]. To overcome the above-mentioned limitations, an ample number of studies has been carried out on sustained drug delivery systems for 5 -fluorouracil.

\footnotetext{
* Corresponding author. Antibiotics Department, Pernambuco Federal University, 50670-901 Recife-PE, Brazil.

E-mail address: flavia_19lucena@yahoo.com.br (F.R.S. Lucena).
}

Rahman et al. prepared and evaluate the colon-specific microspheres of 5-fluorouracil for the treatment of colon cancer. The authors observed that the results clearly indicate that there is great potential in delivery of 5-FU to the colonic region as an alternative to the conventional dosage form [11].

Lekha-Nair et al. studied the biological evaluation of 5fluorouracil nanoparticles for cancer chemotherapy and its dependence on the PLGA carrier (nanoparticles with dependence on the lactide/glycolide combination of PLGA). 5-FU-entrapped PLGA nanoparticles showed smaller size with a high encapsulation efficiency [12]. Horcajada et al. reported the efficiency of some MOFs as carriers of drugs was tested using antiviral and antitumor drugs: bulsufan, azidothymidine-trisfofato, cidovir and doxorubicin. According to the authors, incorporation of some antitumor drugs used for cancers such as leukemia and myeloma into the MIL-100 MOF was considered extremely high. [13]. 
Extensive research within the last two decades has revealed that most chronic illnesses, including cancer, diabetes, and cardiovascular and pulmonary diseases, are mediated through chronic inflammation. Thus, suppressing chronic inflammation has the potential to delay, prevent, and even treat various chronic diseases, including cancer, several drugs including: dexamethasone and doxorubicin have been packaged as nanoparticles and proven to be useful in "nano-chemoprevention" and "nanochemotherapy" $[13,14]$.

Thus in this perspective, this study aimed to evaluate the action mechanism associated with the antitumor activity of the 5fluorouracil incorporated into $\mathrm{Cu}-\mathrm{BTC}$ and a possible antiinflammatory activity, since studies in the literature show a close relationship between inflammation and the appearance of new cancers.

\section{Materials and methods}

\subsection{System drug-MOF used}

The association was performed using 5-FU 99\% (Sigma Aldrich) and the Cu-BTC MOF - BasoliteTM C300 (688814) produced by BASF. First the drug (300 mg) was dissolved in $150 \mathrm{~mL}$ of Milli-Q ultrapure water and $100 \mathrm{mg}$ of Cu-BTC were added, in a proportion of 3:1 (w/w - drug/MOF). The resulting suspension was kept under stirring at room temperature for seven days. Aliquots were removed after seven days, then centrifuged $(4500 \mathrm{rpm})$ for 20 minutes and the supernatant was analysed by UV-Vis spectroscopy to determine the amount of drug present in the metal organic framework. The analysis was performed in triplicate.

\subsection{Chemical characterization}

Elemental analysis (CHNS) measurements were performed in a CE Instruments elemental analyser, model EA1110. FIT-IR spectra were collected from $\mathrm{KBr}$ discs utilizing a Bruker spectrophotometer (IFS-66) with Fourier transform (spectral range 4000 to $400 \mathrm{~cm}^{-1}$ ). The results were analyzed using the OPUS Spectroscopic Software from Bruker. TG/DTG curves were obtained in the temperature range between $20-900{ }^{\circ} \mathrm{C}$ using a Shimadzu TGA 50 thermobalance under a dynamic nitrogen atmosphere $\left(50 \mathrm{~mL} \mathrm{~min}^{-}\right.$ ${ }^{1}$ ) at a heating rate of $10{ }^{\circ} \mathrm{Cmin}^{-1}$ and an alumina crucible containing approximately $3 \mathrm{mg}$ of the sample. The instrument calibration was performed before the tests using a calcium oxalate monohydrate standard, according to the American Society for Testing and Materials. The DSC data were recorded in a DSC 50 cell (Shimadzu) in the $25-600{ }^{\circ} \mathrm{C}$ temperature range under a dynamic nitrogen atmosphere $\left(100 \mathrm{~mL} \mathrm{~min}^{-1}\right)$ in an alumina crucible containing $2.0 \mathrm{mg}$ of the sample; a heating rate of $10^{\circ} \mathrm{C} \mathrm{min}^{-1}$ was used. The powder patter XDR were obtained in a Bruker D8 Advance X-Ray diffract meter $\left(\mathrm{K} \alpha(\mathrm{Cu}) 1,54 \AA\right.$ ), in the range $5^{\circ}$ to $50^{\circ}$, step $0.02^{\circ}$ and acquisition time 1 second.

\subsection{Delivery study (in vitro)}

For in vitro release study was used transparent hard gelatin capsules containing $110.97 \mathrm{mg}$ of incorporation, which was equivalent to $50 \mathrm{mg}$ of 5-FU. Dissolution (dissolutor, Varian, model VK-7000/7010/750D) was performed in PBS (pH: 6.8), volume of $500 \mathrm{~mL}$ at $37^{\circ} \pm 0.5$ and screw speed of 100 RPM. The collections were performed on days $0.5,1.5,5.5,15,20,24,39,44$ and 48 hours. At every given time, a sample was collected from $2.5 \mathrm{~mL}$ to be analyzed on HPLC, followed by replacement of the dissolution medium. The samples were filtered on Millipore ${ }^{\circledR}$ membrane $0.22 \mathrm{~mm}$ in pore size, $13 \mathrm{~mm}$ (Millex). All analyzes were performed in triplicate.
The samples obtained from dissolution studies were individually subjected to analysis by HPLC - DAD using isocratic mobile phase $85 \%$ of acetonitrile: $15 \%$ of water $(\mathrm{v} / \mathrm{v})$ with a $2 \mathrm{~mL} / \mathrm{min}$ flow, the oven temperature was $25^{\circ} \mathrm{C}$, with a stationary phase C18 column $(250 \times 4.6 \mathrm{~mm} / 5 \mu \mathrm{m})$, and $20 \mu \mathrm{L}$ injection volume of the samples. The LC system used was a high performance liquid chromatograph (HPLC) Shimadzu ${ }^{\mathbb{R}}$ equipped with a quaternary pump model LC 20ADVP, powered by helium degasser model DGU - 20A, PDA detector model SPD - 20AVP, oven model CTO-20A SVP, auto sampler model SIL - 20A DVP and controller model SCL - 20AVP. The data were processed by software Shimadzu ${ }^{\circledR}$ LC solution 2.0.

\subsection{Cytotoxic activity and apoptosis tests verification}

The cytotoxic tests were carried out against four cell lines: NCIH292 cells (lung mucoepidermoid carcinoma), MCF-7 cells (breast adenocarcinoma), HT29 cells (colon adenocarcinoma) and HL60 cells (promyelocytic leukemia). The cells were maintained in DMEM - Dulbecco's Modified Eagle Medium. Samples were considered cytotoxic when the rates of cell growth inhibition exceeded $40 \%$, according to the protocol established by Geran [15].

The apoptosis test was done used $5 \mu \mathrm{g} / \mathrm{mL}$ and $10 \mu \mathrm{g} / \mathrm{mL}$. HL60 $(3 \times 105$ cells $/ \mathrm{mL}$ ) were plated onto 24 -well tissue culture plates and treated with (Cu-BTC MOF; 5-fluorouracil (5-FU) and 5$\mathrm{FU}+\mathrm{Cu}-\mathrm{BTC})$. After the $72 \mathrm{~h}$ incubation period, cells were pelleted and resuspended in $1 \times$ Binding Buffer. The pellet was incubated for 10 minutes with $5 \mu \mathrm{L}$ of the annexin-V and $10 \mu \mathrm{L}$ of the propidium iodide (Annexin V-FITC Apoptosis Detection Kit-SIGMA).

Cell fluorescence was determined by flow cytometry in a FACS Calibur cytometer (Becton, Dickinson and Company, New Jersey, USA) using the Cell Quest software. Ten thousand events were evaluated per experiment and cellular debris was omitted from the analysis.

\subsection{Animals used in the pharmacological tests}

For the tests, Swiss albino female mice (Mus musculus) were used, weighing between $30-35 \mathrm{~g}$, with an average age of two months. The animals were monitored according to the norms of the National Institute of Health Guide for Care and Use of Laboratory Animals. The experiments were conducted according to the National Cancer Institute protocol [16] and approved by the UFPE-Animal Experimentation Ethic Committee: 23076.024149/ 2012-48.

\subsection{Peritonitis induced by carrageenan}

In this assay, were used six groups of six animals, treated groups received orally 25,50 and $75 \mathrm{mg} / \mathrm{kg}$ of ( 5 -FU + Cu-BTC MOF). The others group received orally saline vehicle $(0.1 \mathrm{~mL} / 10 \mathrm{~g})$ used as negative control and dexamethasone $(0.5 \mathrm{mg} / \mathrm{kg})$ as positive control. One hour after the treatment, the inflammation was induced by intraperitoneal (i.p) application of $0.1 \mathrm{~mL} / 10 \mathrm{~g}$ of carrageenan ( $1 \%$ in saline solution).

After 4 hours the animals were euthanized in a chamber of $\mathrm{CO}_{2}$ so was injected into the peritoneal cavity $3 \mathrm{~mL}$ of phosphate buffered saline PBS containing EDTA to collect the peritoneal fluids. The total leukocyte number was determined in hematology analyzer Micros $60^{\circledR}$. The exudates were centrifuged and the supernatant stored at $-20{ }^{\circ} \mathrm{C}$ for analysis of nitric oxide and citokines levels [17].

\subsection{Analysis of nitric oxide production}

The nitrite accumulated in the samples was measured as an indicator of NO production using the Griess reaction. Briefly, the 
samples were mixed with an equal volume of Griess reagent in a 96-well microtiter plate and incubated at room temperature for 10 minutes. The absorbance was read at $540 \mathrm{~nm}$ using an ELISA reader and the nitrite concentrations were determined by comparison with a standard curve of sodium nitrite [17].

\subsection{Measurement of cytokines}

The concentrations of TNF- $\alpha$ and IL- $1 \beta$ were measured using sandwich ELISA kits, specific for mice, according to the manufacturer's instructions (eBioscience, San Diego, California, USA). The detection limit used was $8-1000 \mathrm{pg} / \mathrm{mL}$. The experiments were done in triplicate [18].

\subsection{Statistical analysis}

The results are presented as mean \pm standard deviation (SD). Data were analyzed using the software graph pad prism v 5.0 Oneway ANOVA followed by the Newman-Keuls test were used to evaluate the differences among the treatments. $P$ values $<0.05$ were considered statistically significant.

\section{Results and discussion}

Drug loading, expressed in g 5-FU per gram Cu-BTC, after seven days of stirring was 0.8221 . The $\mathrm{Cu}-\mathrm{BTC}$ MOF contains $\mathrm{C}, \mathrm{O}$ and $\mathrm{H}$ atoms but lacks $\mathrm{N}$ atoms, therefore, the presence of the drug on this structure was indicated by the appearance of $\mathrm{N}$ atoms in the elemental analysis. The theoretical and experimental results are represented in Table 1 and conform to the proportions demonstrated in the TGA analysis.

Fig. 1 shows the FTIR spectra of the precursors and the product obtained. In the infrared spectrum of Cu-BTC, there is a very strong band centered at $3450 \mathrm{~cm}^{-1}$ assigned to the $\mathrm{OH}$ stretching from water molecules. The broadness of this band is consistent with extensive hydrogen bonding from both coordinated and noncoordinated water molecules. Bands at $1644 \mathrm{~cm}^{-1}$ and $1373 \mathrm{~cm}^{-1}$ are assigned to asymmetric and symmetric (OCO-) stretching from carboxylate groups. Additional bands at 1587 and $1450 \mathrm{~cm}^{-1}$ are due to $\mathrm{C}=\mathrm{C}$ stretching from the aromatic rings. The FTIR spectrum for 5-FU is characterized by a broad band at $3133 \mathrm{~cm}^{-1}$, assigned to $\mathrm{NH}$ stretching, in addition to bands at $1724 \mathrm{~cm}^{-1}$ and $1660 \mathrm{~cm}^{-1}$ arising from the two distinct carbonyl groups in 5-FU structure. The spectrum for Cu-BTC/5-FU sample shows bands from both host and guest species, some of them shifted due to the occurrence of intermolecular interactions. The spectrum exhibits the $\mathrm{NH}$ stretching band centered at $3150 \mathrm{~cm}^{-1}$ and at higher wave numbers an envelope of $\mathrm{OH}$ stretching bands (centered at 3550, 3498,3460 and $3388 \mathrm{~cm}^{-1}$ ). Those bands are probably due to the coordinated water molecules, which were partially resolved after removal of the non-coordinated ones during the association process, as shall be discussed on the basis of thermal analysis. At lower wave numbers, we can observe the carbonyl bands from 5FU at 1708 and $1660 \mathrm{~cm}^{-1}$ in addition to the carboxylate bands

Table 1

CNHS elemental analysis.

\begin{tabular}{lcccc}
\hline Sample & $\% \mathrm{~N}$ & $\% \mathrm{C}$ & $\% \mathrm{H}$ & $\% \mathrm{~S}$ \\
\hline Theoretical & & & & \\
$\quad$ Cu-BTC & 0.0 & 25.8 & 4.3 & 0.0 \\
$\quad$ Cu-BTC/5-FU & 2.4 & 30.2 & 3.0 & 0.0 \\
$\quad$ & & & & \\
Experimental & 0.0 & 26.3 & 3.7 & 0.0 \\
$\quad$ Cu-BTC. 12 $\mathrm{H}_{2} \mathrm{O}$ & 2.5 & 30.7 & 2.8 & 0.0 \\
$\quad$ Cu-BTC. $6 \mathrm{H}_{2} \mathrm{O}+0.82$ 5-FU & & &
\end{tabular}

CU-BTC: $\mathrm{C}_{18} \mathrm{H}_{6} \mathrm{Cu}_{3} \mathrm{O}_{12} / 5-\mathrm{FU}-\mathrm{C}_{9} \mathrm{H}_{3} \mathrm{FN}_{2} \mathrm{O}_{2}$.

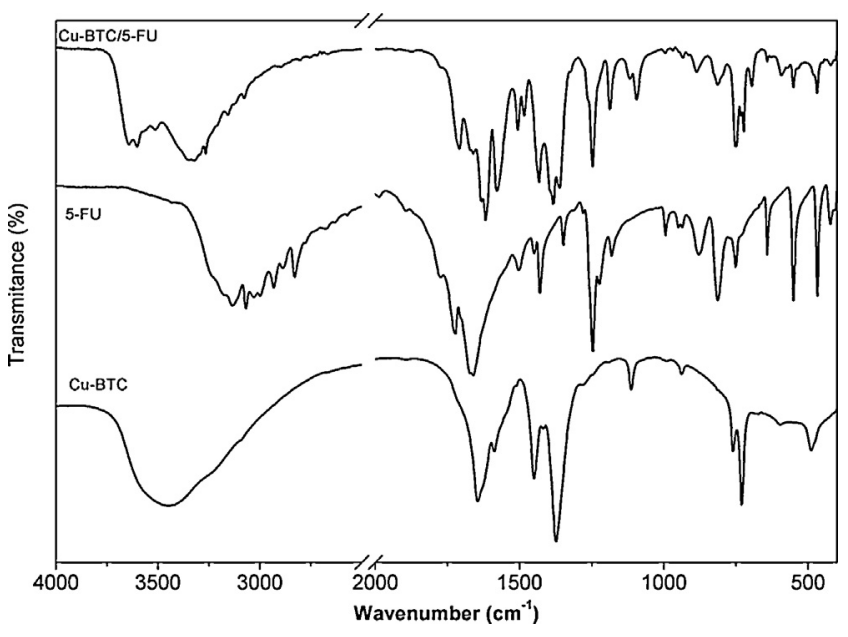

Fig. 1. FTIR spectra of $\mathrm{Cu}-\mathrm{BTC}$ MOF.

from Cu-BTC at 1631,1617 and $1382 \mathrm{~cm}^{-1}$. Bands from both species in this region are slightly shifted as mentioned [19].

Thermal analysis data complemented characterization allowing us to make a picture of the sample Cu-BTC/5-FU. Fig. 2 shows DSC curves for the drug 5-fluorouracil, showing that the free drug starts to decompose at nearly $260{ }^{\circ} \mathrm{C}$ with a peak in DTG at $303^{\circ} \mathrm{C}$. DSC for 5 -FU shows that actually the solid drug melts at $279{ }^{\circ} \mathrm{C}$ and decomposes subsequently after melting.

Analyzing the thermal analysis curves TG/DTG (Fig. 3) and DSC (Fig. 2) for Cu-BTC, we see that the sample starts to lose adsorbed and non-coordinated water molecules below $100{ }^{\circ} \mathrm{C}$. After losing nearly $30 \%$ of the whole mass, the TG curve shows a plateau from $150{ }^{\circ} \mathrm{C}$ which is disturbed by very discrete mass losses at $160{ }^{\circ} \mathrm{C}$

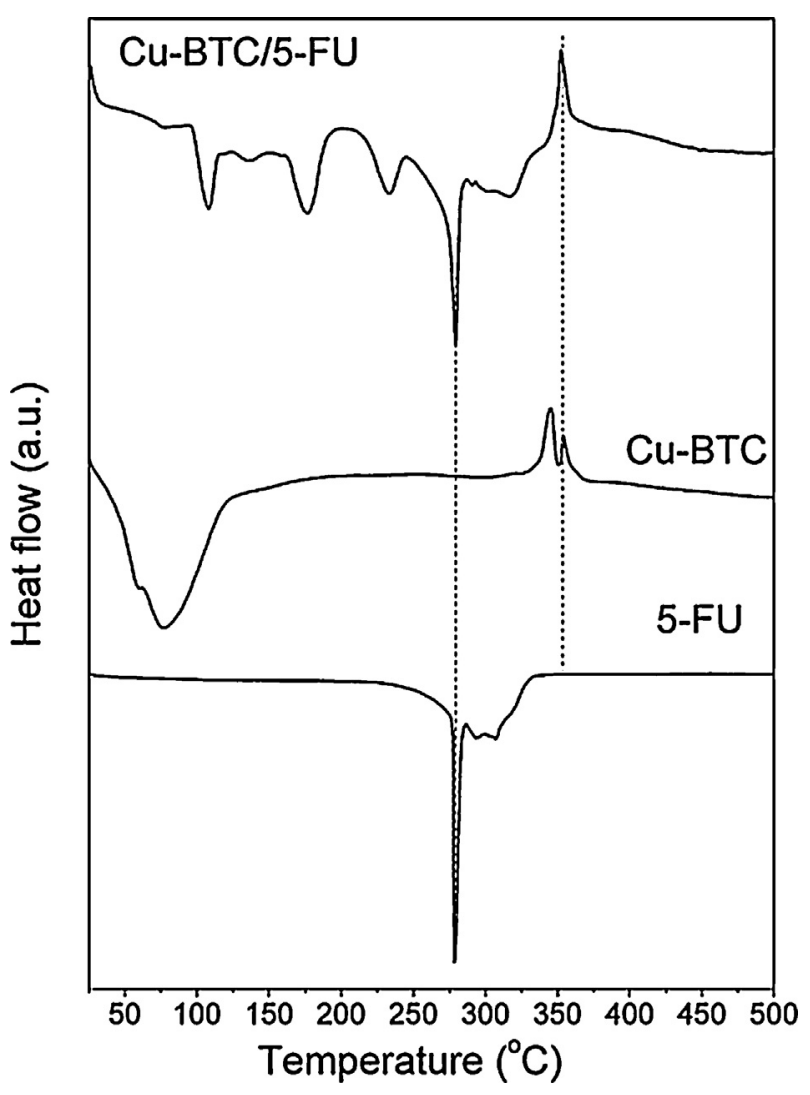

Fig. 2. DSC curves Cu-BTC/5-FU; Cu-BTC; 5-FU. 

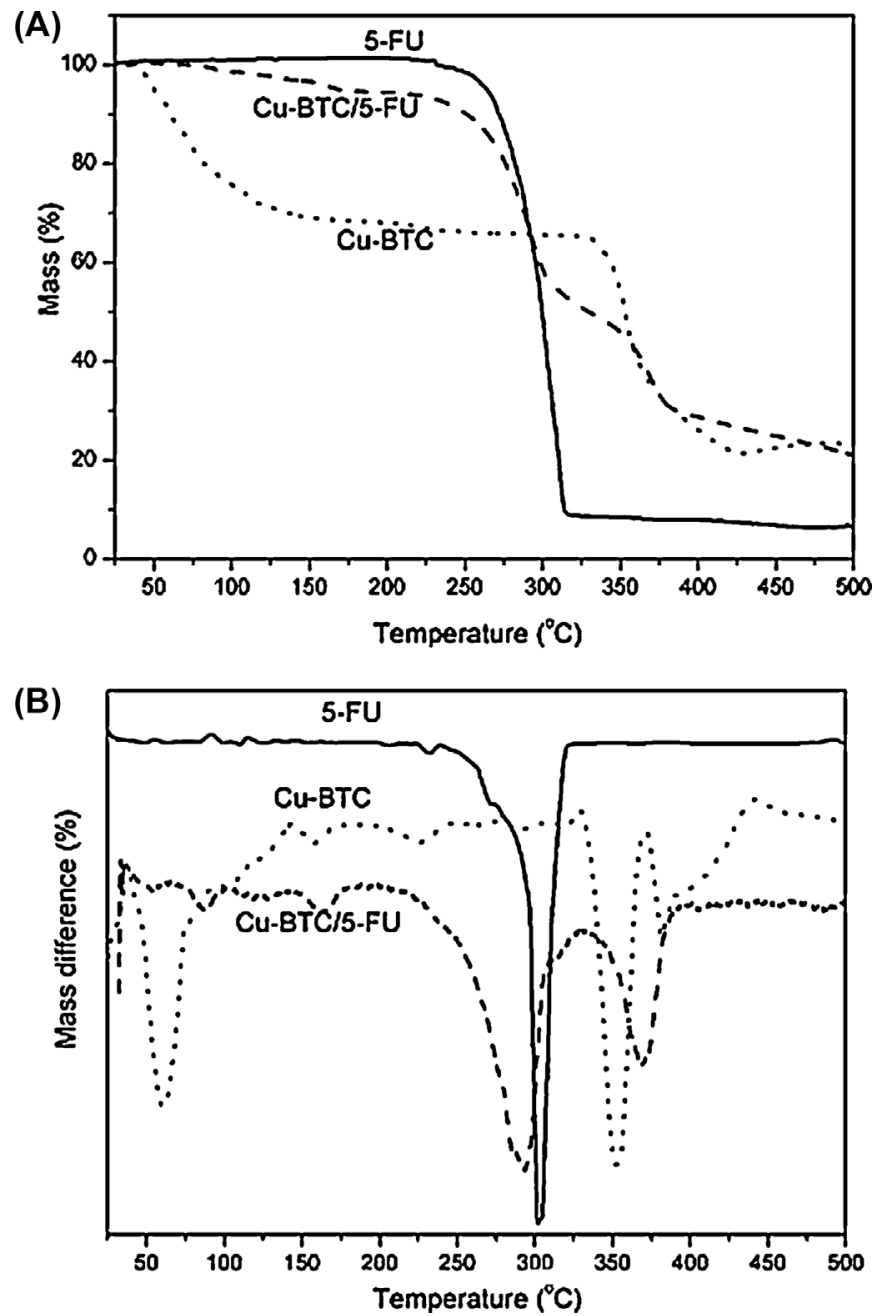

Fig. 3. Thermal analysis curves TG (A) and DTG (B) for 5-FU; $\mathrm{Cu}-\mathrm{BTC}$ and $\mathrm{Cu}-\mathrm{BTC} / 5-$ FU.

and $225^{\circ} \mathrm{C}$, followed by a major mass loss starting from $320^{\circ} \mathrm{C}$ (peaked at $352{ }^{\circ} \mathrm{C}$ and $381{ }^{\circ} \mathrm{C}$ in the DTG curve), assigned to decomposition of the framework structure. This event can be assigned to both decomposition of the organic ligands and release/ decomposition of the coordinated water molecules. In the Cu-BTC DSC curve these events are observed as a broad endothermic event centered at $77{ }^{\circ} \mathrm{C}$ along with two exothermic ones at 344 and $354{ }^{\circ} \mathrm{C}$. Finally for the $\mathrm{Cu}-\mathrm{BTC} / 5-\mathrm{FU}$ sample, the thermal analysis curves show interesting features.

TG curve shows that the initial thermal event observed for the original MOF is absent which suggests that the non-coordinated water molecules originally present in the pores are probably replaced for 5-FU molecules during the association process [20]. This is also consistent with observations made from FTIR analysis. A very small mass loss is observed at $163^{\circ} \mathrm{C}$, which can be related to trace residual non-coordinated water molecules, followed by a significant loss at 286 and $294^{\circ} \mathrm{C}$. The last event is probably related to decomposition of 5-FU and considering that the peak is broad and shows two unresolved minima, it suggests two structural situations for this molecule (see DSC discussion). Another mass loss is observed at $370{ }^{\circ} \mathrm{C}$ due to the decomposition of the MOF. Both the decomposition of the host and of the guest are shifted in comparison with the free samples.

From DSC curve for Cu-BTC/5-FU (Fig. 2), we can observe the presence of several endothermic events $\left(108,177,233,279^{\circ} \mathrm{C}\right)$ along with an exothermic event at $352^{\circ} \mathrm{C}$. The sharp endothermic

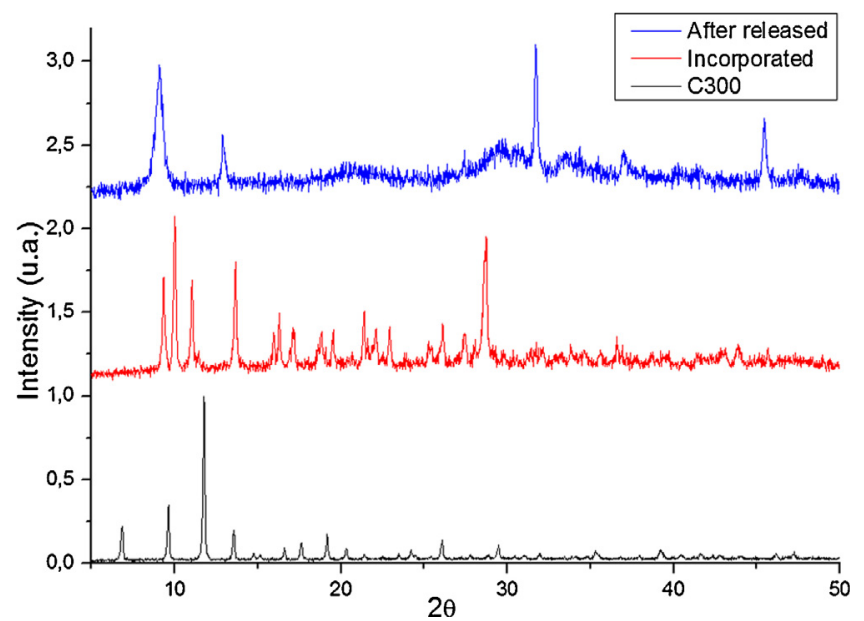

Fig. 4. Powder pattern XDR (black: C300) - Cu-BTC MOF; (red: incorporated) - CuBTC/5-FU and (blue: after release) - sample after dissolution test.

event at $279{ }^{\circ} \mathrm{C}$ (drug melting) suggests that despite a careful isolation procedure, some 5-FU crystals may have remained some free molecules (possibly physical adsorbed) in Cu-BTC/5-FU sample. Although previous works with other MOFs having larger pores suggested that several molecules could occupy the pores and the surface area. Thus we propose here that our sample contains a slight fraction of 5-FU crystals, probably as a result of the equilibrium between the free and associated species which makes difficult a complete purification. Despite this, it is clear that drug association with the metal organic framework (Cu-BTC) occurs to a great extent as can be inferred from significant changes in the DSC curve, in special in the interval of water release and MOF decomposition.

The adsorption process results from the interaction between the guest molecule and the adsorbent material, in our case, the $\mathrm{Cu}$ BTC and 5-FU. Those interactions, in general, are very week (physisorption), but, in some cases, the host-gest interactions affinity is strong and due the chemisorption and structural changes may occur. In this perspective, the X-ray powder diffraction becomes a powerful tool to investigate those crystalline transformations.

The Fig. 4 (in black) shows the experimental powder pattern of the $\mathrm{Cu}-\mathrm{BTC}$ used in the 5-FU incorporation. This diffractogram, as expected, shows all peaks corresponding to the $\left[\mathrm{Cu}_{2}(\mathrm{BTC})_{3}\left(\mathrm{H}_{2} \mathrm{O}\right)_{3}\right]$ structure (cubic, space group Fm-3 m) synthesized by Williams et al. [12]. The most intense peaks are located in $11.6^{\circ}, 9.5^{\circ}$ and $6.7^{\circ}$ related to the [222], [220] and [200] diffraction plans, respectively. After the drug incorporation, the samples was collected the powder pattern, and the result (Fig. 4 , in red) shows different diffraction peaks regarding to the $\mathrm{Cu}-\mathrm{BTC}$. Although the sample still has strong crystalline character, this result suggests that there was a structural change in the $\mathrm{Cu}-\mathrm{BTC}$ during the incorporation process, probably due to the supramolecular interactions between the drug and the MOF.

The drug incorporation is confirmed by the intense signal located in $28.8^{\circ}$, related to the [220] diffraction plane of the 5-FU, in agreement with the literature [21,22]. This observation is in good agreement with IR-spectroscopy, TGA and elementary analysis results. After the dissolution test, the incorporated 5FU was released and, again, was collected the powder pattern, shown in the Fig. 4 (in blue). As expected, was not observed the diffraction peak of the drug, which is in good agreement with the dissolution test results, and once again, was detected structural changes in the $\mathrm{Cu}-\mathrm{BTC}$, experiencing a slight amorphization in the structure. 


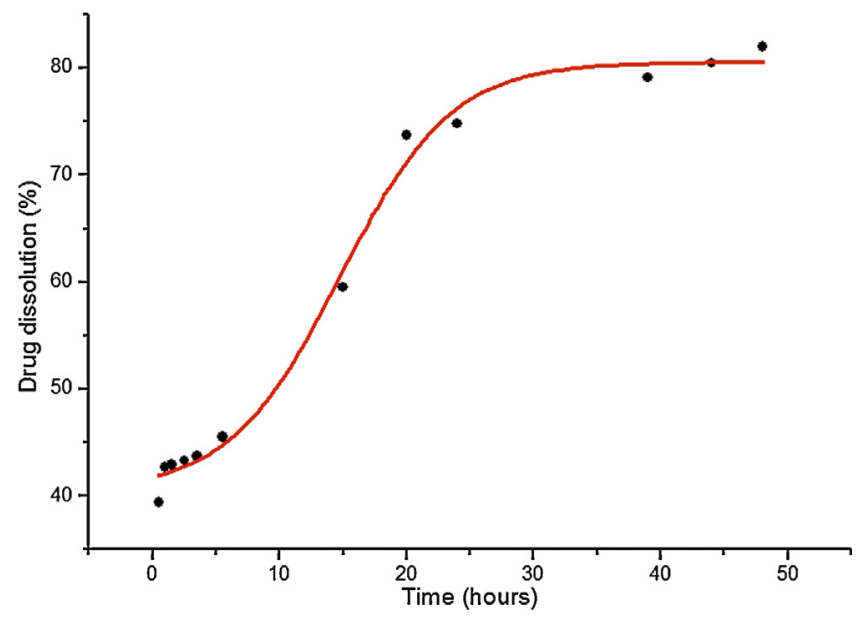

Fig. 5. Dissolution profile of 5-fluorouracil from Cu-BTC MOF.

The release profile was conducted in order to ascertain whether the drug is output from the system in the physiological environment. The experiment demonstrated during the prolonged drug release 48 hours. Initially, $39.4 \%$ of the drug was released from the MOF in the first 30 minute; this can be attributed to the drug in its free form as indicated in DSC curve. Then, the release proceeded more slowly being released about $60 \%$ in 15 hours of study, the dissolution reached $82.0 \%$ at 48 hours.

The release of 5-FU "in vitro" found in our system resembles the one extended release "in vivo", which are offered two doses of the drug (Fig. 5). The first, called immediate-release initial dose, required to produce the desired pharmacological effect without causing damage to the body. The second, called maintenance dose, is released gradually, in order to prolong the extent of pharmacological response [23].

Table 2 shows the IC50 values for inhibition of cellular activity of at least 70\%. We observed that 5-fluorouracil exhibited cytotoxic activity against MCF-7 and HL-60 cells. The IC50 value for the MCF7 cells was very low $(1.735 \mu \mathrm{g} / \mathrm{mL})$ when the drug was associated with the MOF, this can be attributed to prolonged drug release as indicated in dissolution study, allowing the maintenance of the biological effect, since the active principle of the drug being released slowly and continues.

The same was true for the HL-60 cells. The IC50 values decreased significantly when the drug was associated with the network, suggesting that the association between the 5-fluorouracil and the $\mathrm{Cu}$-BTC MOF are responsible by the modulation of the cytotoxic activity of the drug (Table 2).

The apoptosis test demonstrated that 5-fluorouracil incorporated into $\mathrm{Cu}$-BTC MOF induced cell death by apoptosis mechanism to the dose of $10 \mu \mathrm{g} / \mathrm{mL}$ (Fig. 6). These results are according with the peritonitis test that showed a decrease in levels of TNF- $\alpha$ and NO in the tumor site, which may have contributed to the maintenance of the required levels of these substances in the activation of caspase that activate apoptosis. Experience since then

Table 2

IC50 $(\mu \mathrm{g} / \mathrm{mL})$ compared to the human tumor lines.

\begin{tabular}{llll}
\hline Cell line & CU-BTC & $5-\mathrm{FU}$ & Cu-BTC/5-FU \\
\hline MCF-7 & $3.49^{\mathrm{a}}$ & 20 & $1.735^{\mathrm{b}}$ \\
HT-29 & $>25$ & $>25$ & $>25$ \\
HL-60 & $>25$ & 8.601 & 4.615 \\
NCI-H292 & $>25$ & $>25$ & $>25$ \\
\hline
\end{tabular}

a Very toxic.

b Toxic.

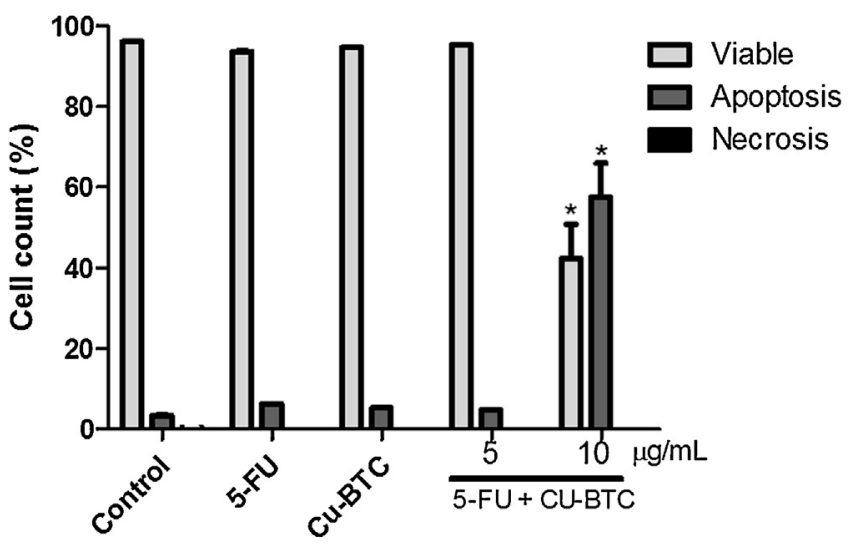

Fig. 6. Checking mechanism necrosis $\times$ apoptosis by flow cytometry.

has indicated that when expressed locally by the cells of the immune system, TNF- $\alpha$ has a therapeutic role, however when dysregulated and secreted in the circulation, TNF- $\alpha$ can mediate a wide variety of diseases, including cancer [24]. TNF- $\alpha$ has itself been shown to be one of the major mediators of inflammation is also produced by tumors and can act as an endogenous tumor promoter. The role of TNF- $\alpha$ has been linked to all steps involved in tumorigenesis, including cellular transformation, promotion, survival, proliferation, invasion, angiogenesis, and metastasis [25].

Considering this information, the results found in our experiments demonstrated that 5-fluorouracil associated with MOF CuBTC may have favored the process of induction of cell death by apoptosis.

Currently inflammatory processes are rather taken into consideration when one wants to get success in antitumor therapies, chronic inflammation that because of some organ, like the liver, increases the number of cell divisions and thus the risk of mutations. Tumor cells produce various cytokines and chemokines that attract leukocytes [26]. The direct evidence for the association of chronic inflammation with malignant diseases is in colon carcinogenesis in individuals with inflammatory bowel diseases [27]. The emerging concept in clinical trials reveals that inflammation is a potential therapeutic target in cancer treatment and anti-inflammatory drugs are thereby potentially useful as adjuvant therapy [24].

The peritonitis tests was conducted in order to verify the process of secondary mechanism of action by which the drug embedded in coordination network has its cytotoxic activity which may be enhanced by modulation of immune cells such as polymorphonuclear leukocytes. Through this test, we suggest that the cytotoxic and antitumor activity of the drug is related to the route of leukocyte activation or suppression of the inflammatory process, which is closely related to the processes related to tumor angiogenesis, parallel production of inflammatory interleukins and TNF- $\alpha$, IL-6 among others [25].

The results showed that a possible way of action of the drug incorporated in the network to coordinate the performance of this system is as an anti-inflammatory agent, since it caused a reduction of inflammation in $43.7,64$ and $66.8 \%$ respectively for doses of 25,50 and $75 \mathrm{mg} / \mathrm{kg}$ when compared to negative control group with inflammation induced by carrageenan $1 \%$ in saline. The inhibition of leukocyte data is described in Fig. 7.

Tumor-associated macrophages are a significant component of inflammatory infiltrates in neoplastic tissues and are derived from monocytes that are recruited largely by monocyte chemotactic protein (MCP) chemokines. The pro-inflammatory cytokines, including tumor necrosis factor-alpha (TNF- $\alpha$ ) and interleukin-6 (IL-6), induce direct effects on stromal and neoplastic cells in addition to their roles in regulating leukocyte recruitment [14]. 


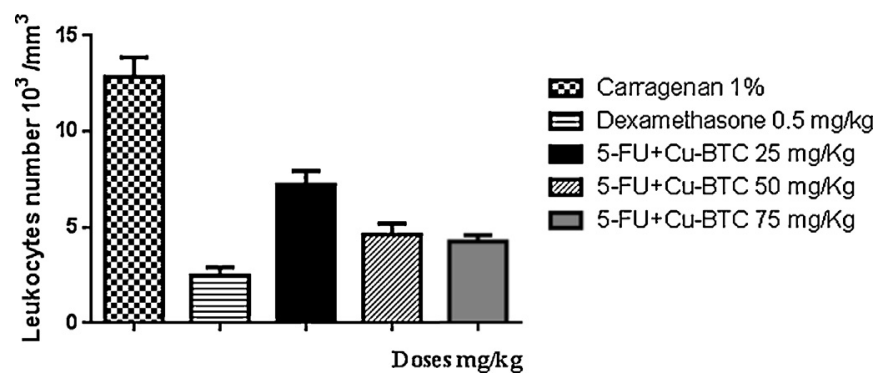

Fig. 7. Peritonitis test leukocytes number $\times$ doses of $5-\mathrm{FU}+\mathrm{Cu}-\mathrm{BTC}$.

Table 3

Effect of 5-FU + CuBTC on the NO production in the carrageenan test.

\begin{tabular}{lc}
\hline Treatment & NO $(\mu \mathrm{M})$ \\
\hline Control group & $21.30 \pm 3.62$ \\
Dexamethasone & $1.77 \pm 0.44^{\mathrm{a}}$ \\
$25 \mathrm{mg} / \mathrm{kg}(5-\mathrm{FU}+\mathrm{Cu}-\mathrm{BTC})$ & $0,78 \pm 0.07^{\mathrm{a}}$ \\
$75 \mathrm{mg} / \mathrm{kg}(5-\mathrm{FU}+\mathrm{Cu}-\mathrm{BTC})$ & $0,63 \pm 0.02^{\mathrm{a}}$ \\
\hline
\end{tabular}

Data are expressed by mean standard deviation (mean \pm standard deviation).

a Statistically significant difference compared to control $(P<0.05)$.

Table 4

Effect of 5-FU + CuBTC on the TNF- $\alpha$ e IL- $1 \beta$ productions in the carrageenan test induced peritonitis.

\begin{tabular}{lcl}
\hline Compound & TNF- $\alpha(\mathrm{pg} / \mathrm{mL})$ & IL-1 $\beta(\mathrm{pg} / \mathrm{mL})$ \\
\hline Control & $502.11 \pm 3.31$ & $751.00 \pm 15.04$ \\
Dexamethasone & $126.39 \pm 13.15^{\mathrm{a}}$ & $289.35 \pm 18.62^{\mathrm{a}}$ \\
$75 \mathrm{mg} / \mathrm{kg}(5-\mathrm{FU}+\mathrm{Cu}-\mathrm{BTC})$ & $117.39 \pm 37.86^{\mathrm{a}}$ & $238.70 \pm 5.62^{\mathrm{a}}$ \\
$25 \mathrm{mg} / \mathrm{kg}(5-\mathrm{FU}+\mathrm{Cu}-\mathrm{BTC})$ & $300.9 \pm 26.11^{\mathrm{a}}$ & $617.18 \pm 12.62^{\mathrm{a}}$ \\
\hline
\end{tabular}

Data are expressed by mean standard deviation (mean \pm standard deviation).

a Statistically significant difference compared to control $(P<0.05)$.

The direct evidence for the association of chronic inflammation with malignant diseases is in colon carcinogenesis in individuals with inflammatory bowel diseases [25]. The emerging concept in clinical trials reveals that inflammation is a potential therapeutic target in cancer treatment and antiinflammatory drugs are thereby potentially useful as adjuvant therapy [28].

The exudates removed from the abdominal cavity of the animals subjected to the test of carrageenan induced peritonitis were analyzed and levels of nitric oxide and pro-inflammatory cytokines have been shown in Tables 3 and 4 . It was observed that there was a statistically significant decrease in NO production and cytokine treated groups when considered in doses of 25 and $75 \mathrm{mg} / \mathrm{kg}$ of body weight.

These results being in agreement with the results on the number of white blood cells found in the peritoneal cavity animals, indicating a possible anti-inflammatory action of this system.

\section{Conclusions}

As noted in the results obtained, 5-fluorouracil incorporated into the Cu-BTC MOF appears to be a great tool in the treatment of cancer, since we obtained a rate optimal encapsulation, together with a controlled release of drug from the nanocarrier.

Nanoparticle therapeutics is an emerging treatment modality in cancer and other inflammatory disorders. The National Cancer Institute has recognized nanotechnology as an emerging field with the potential to revolutionize modern medicine for detection, treatment, and prevention of cancer [29]. More selective therapies, such as angiogenesis inhibitors, vascular disrupting agents, and estrogenic HER-2-targeted therapies have been developed to treat cancer, these approaches have increased patient survival because of treatment efficacy [30].

Most solid tumors possess unique features, including enhanced angiogenesis, defective vasculature and lymphatic, increased vascular permeability, which stimulate their growth. Rationally designed nanoparticles can take advantage of these tumor features to deliver chemotherapeutics selectively and specifically [14].

These results together the death of cancer cells through the mechanism of apoptosis and anti-inflammatory activity associated with decreased levels of the pro-inflammatory cytokines, directly related to the maintenance of chronic inflammation processes, indicate this system as a viable alternative when considering an ideal system for cancer treatment, since it showed the controlled release properties, low toxicity to normal cells and also an indication of anti-inflammatory activity which could act as an adjuvant treatment [30].

\section{Disclosure of interest}

The authors have not declared any conflicts of interest.

\section{References}

[1] Cai C, Zhou K, Wu Y, Wu L. Enhanced liver targeting of 5-fluorouracil using galactosylated human serum albumin as a carrier molecule. J Drug Target 2006;14:55-61

[2] Cao S, Rustum YM. Synergistic antitumor activity of irinotecan in combinationwith 5-fluorouracil in rats bearing advanced colorectal cancer: role of drug sequence and dose. Cancer Res 2000;60:3717-21.

[3] Kubota T. Recent progress in combination therapy of low-dose CDDP/5-FU in Japan. Theoretical basis for low-dose CDDP/5-FU therapy. Jpn J Cancer Chemother 1999;26:1536-41.

[4] Shapiro WR, Green SB, Burger PC, et al. A randomized comparison of intraarterial versus intravenous with or without intravenous 5-fluorouracil, for newly diagnosed patients with malignant glioma. J Neurosurg 1992;76:77281.

[5] Hutchins LF, Green SJ, Ravdin PM, et al. Randomized, controlled trial of cyclophosphamide, methotrexate, and fluorouracil versus cyclophosphamide, doxorubicin, and fluorouracil with and without tamoxifen for high-risk, nodenegative breast cancer: treatment results of Intergroup Protocol INT-0102. J Clin Oncol 2005;23:8313-21.

[6] Longley DB, Harkin DP, Johnston PG. 5-fluorouracil: mechanisms of action and clinical strategies. Nat Rev Cancer 2003:3:330-8.

[7] Parker WB, Cheng YC. Metabolism and mechanism of action of 5-fluorouracil Pharmacol Ther 1990;48:381-95.

[8] Fata F, Ron IG, Kemeny N, O’Reilly E, Klimstra D, Kelsen DP. 5-fluorouracilinduced small bowel toxicity in patients with colorectal carcinoma. Cancer 2000;86:1129-34

[9] Paolo AD, Danesi R, Falcone A, et al. Relationship between 5-fluorouracil disposition, toxicity and dihydropyrimidine dehydrogenase activity in cancer patients. Ann Oncol 2001;12:1301-6.

[10] van Kuilenburg ABP, Haasjes J, Richel DJ, et al. Clinical implications of dihydropyrimidine dehydrogenase (DPD) deficiency in patients with severe 5fluorouracil-associated toxicity: identification of new mutations in the DPD gene. Clin Cancer Res 2000;6:4705-12.

[11] Rahman Z, Kohli K, Khar RK, Ali M, Charoo NA, Shamsher AAA. Characterization of 5-fluorouracil microspheres for colonic delivery. AAPS Pharm Sci Tech 2006;7(2):E1-9.

[12] Nair LK, Jagadeeshan S, Nair SA, Vinod Kumar GS. Biological evaluation of 5fluorouracil nanoparticles for cancer chemotherapy and its dependence on the carrier, PLGA. Int J Nanomed 2011;6:1685-97.

[13] Horcajada P, Chalati T, Serre C, Gillet B, Sebrie C, Baati T, et al. Porous metalorganic framework nanoscale carriers as a potencial platform for drug delivery and imaging. Nat Mater 2010;9:172-8.

[14] Nair HB, Sung B, Yadav VR, Kannappan R, Chaturvedi MM, Aggarwal BB. Delivery of anti-inflammatory nutraceuticals by nanoparticles for the prevention and treatment of cancer. Biochem Pharmacol 2010;80(12):1833-43.

[15] Geran RI, Greenberg NH, Macdolnald MM, Schumacher AM, Abbott BJ. Protocols for screening chemical agents and natural products against animal tumors and other biological systems. Cancer Chemother 1972 [Rep. 3. protocols 16 and 13].

[16] www1.inca.gov.br/inca/arquivos/bioterio.pdf.

[17] Uchôa FT, Silva TG, Lima MCA, Galdino SL, Pitta IR, Costa TD. Preclinical pharmacokinetic and pharmacodynamic evaluation of thiazolidinone PG15: an anti-inflammatory candidate. J Pharm Pharmac 2009;61:339-45.

[18] Aggarwal BB. Sinalling pathways of the TNF superfamily: a double-edged sword. Nat Rev Immunol 2003;3(9):745-56. 
[19] Campos J, Domínguez JF, Gallo MA, Espinosa A. From a classic approach in cancer chemotherapy towards differentiation therapy: acyclic and cyclic seven-membered 5-fluorouracil O,N-acetals. Curr Pharm Des 2000;6:1797.

[20] Chui SSY, Lo SMF, Charmant JPH, Orpen AG, Williams ID. A chemically functionalizable nanoporous material $\left[\mathrm{Cu}_{3}(\mathrm{TMA})_{2}\left(\mathrm{H}_{2} \mathrm{O}\right)_{3}\right]_{n}$. Science 1999;26:1148-50.

[21] Dhawale SC, Bankar AS, Patro MN. Formulation and evaluation porous microspheres of 5-fluorouracil for colon targeting. Int J PharmTech Res 2010;2:1112-8.

[22] Aggarwal BB, Shishodia S, Sandur SK, Pandey MK, Sehti G. Inflammation and cancer: how hot is the link? Biochem Pharmac 2006;2:1605-21.

[23] Ansel HC, Allen Jr LV, Popovich NG. Formas farmacêuticas e sistemas de liberação de fármacos, 8th ed., Porto Alegre: Artmed; 2007.

[24] Longhi-balbinot DT, Lanznaster D, Baggio CH, Silva MD, Cabrera CH, Facundo VA, et al. Anti-inflammatory effect of triterpene $3 \beta, 6 \beta, 16 \beta$-trihydroxylup20(29)-ene obtained from Combretum leprosum Mart \& Eich in mice. J Ethnoph 2012;142(1):59-64.
[25] Amin AR, Kucuk O, Khuri FR, Shin DM. Perspectives for cancer prevention with natural compounds. J Clin Oncol 2009;27:2712-25.

[26] Itzkowitz SH, Yio X, Inflammation, cancer IV. Colorectal cancer in inflammatory bowel disease: the role of inflammation. Am J Physiol Gastrointest Liver Physiol 2004:287:G7-17.

[27] Danese S, Mantovani A. Inflammatory bowel disease and intestinal cancer: a paradigm of the Yin-Yang interplay between inflammation and cancer. Oncogene 2010;29:3313-23.

[28] Kawasaki ES, Player A. Nanotechnology, nanomedicine, and the development of new, effective therapies for cancer. Nanomedicine 2005;1:101-9.

[29] Anand P, Sundaram C, Jhurani S, Kunnumakkara AB, Aggarwal BB. Curcumin and cancer: an "old-age" disease with an "age-old" solution. Cancer Lett 2008;267:133-64.

[30] Sun D, Zhuang X, Xiang X, Liu Y, Zhang S, Liu C, et al. A novel nanoparticle drug delivery system: the anti-inflammatory activity of curcumin is enhanced when encapsulated in exosomes. Mol Ther 2010;18(9):1606-14. 